\title{
Long-term outcomes following intraosseous basivertebral nerve ablation for the treatment of chronic low back pain: 5-year treatment arm results from a prospective randomized double-blind sham-controlled multi-center study
}

\author{
Jeffrey S. Fischgrund ${ }^{1}\left(\right.$ ) $\cdot$ Alfred Rhyne ${ }^{2} \cdot$ Kevin Macadaeg $^{3} \cdot$ Gregory Moore $^{4} \cdot$ Evish Kamrava $^{5} \cdot$ Christopher Yeung $^{6}$. \\ Eeric Truumees $^{7} \cdot$ Michael Schaufele $^{8} \cdot$ Philip Yuan $^{9} \cdot$ Michael DePalma $^{10} \cdot$ David Greg Anderson $^{11}$. \\ Douglas Buxton $^{12} \cdot$ James Reynolds $^{13} \cdot$ Michael Sikorsky $^{14}$
}

Received: 16 December 2019 / Revised: 21 March 2020 / Accepted: 2 May 2020 / Published online: 25 May 2020

(C) The Author(s) 2020

\begin{abstract}
Background Damaged or degenerated vertebral endplates are a significant cause of vertebrogenic chronic low back pain (CLBP). Modic changes are one objective MRI biomarker for these patients. Prior data from the treatment arm of a shamcontrolled, RCT showed maintenance of clinical improvements at 2 years following ablation of the basivertebral nerve (BVN). This study reports 5-year clinical outcomes.

Methods In total, 117 US patients were treated successfully with BVN ablation. Patient-reported outcomes of ODI, VAS, postablation treatments, and patient satisfaction were collected at a minimum of 5-years following BVN ablation. Primary outcome was mean change in ODI. Comparisons between the postablation and baseline values were made using an analysis of covariance with alpha 0.05 .

Results Of the 117 US treated patients 100 (85\%) were available for review with a mean follow-up of 6.4 years (5.47.8 years). Mean ODI score improved from 42.81 to 16.86 at 5 -year follow-up, a reduction of 25.95 points $(p<0.001)$. Mean reduction in VAS pain score was 4.38 points (baseline of $6.74, p<0.001$ ). In total, $66 \%$ of patients reported a $>50 \%$ reduction in pain, $47 \%$ reported a $>75 \%$ reduction in pain, and $34 \%$ of patients reported complete pain resolution. Composite responder rate using thresholds of $\geq 15$-point ODI and $\geq 2$-point VAS for function and pain at 5 years was $75 \%$.

Conclusion CLBP patients treated with BVN ablation exhibit sustained clinical improvements in function and pain with high responder rates at a mean of 6.4 years following treatment. BVN ablation is a durable, minimally invasive treatment for vertebrogenic CLBP.
\end{abstract}

Keywords Chronic low back pain $\cdot$ Basivertebral nerve $\cdot$ Radiofrequency ablation $\cdot$ Modic $\cdot$ Randomized controlled trial

\section{Introduction}

Vertebrogenic pain from degenerated or damaged vertebral endplates is an important source of chronic low back pain (CLBP) [1-6]. Studies have shown that damaged endplates allow for proinflammatory material from the nucleus pulposus to diffuse into the adjacent marrow, inciting an inflammatory cascade that results in bone marrow changes (Modic changes) and neovascularization $[2,4,7$,

Jeffrey S. Fischgrund

jsfischgrund37@gmail.com

Extended author information available on the last page of the article
8]. Immunohistochemical and anatomical studies have demonstrated endplate nociceptors with afferents to the basivertebral nerve (BVN), a branch of the sinuvertebral nerve located within the posterior vertebral body (VB) [6, 9]. Densification of these nerves has been demonstrated in endplates with Modic Type I or II changes. In the presence of chemical or mechanical sensitization, pain signals from damaged endplates are transmitted to the central nervous system via the BVN and perceived as CLBP [1]. These findings led to the development of intraosseous ablation of the BVN using $\mathrm{RF}$ energy for the treatment of vertebrogenic CLBP.

Current BVN ablation evidence demonstrates consistent short- to intermediate-term improvements in function 
and pain. In addition to two prospective single-arm studies reporting clinically significant improvements in ODI and VAS from baseline [10, 11], two level 1 randomized controlled trials (RCTs) have demonstrated superiority over standard care at 3 months [12] and over sham control at 12 months [13].

Long-term outcomes (beyond 2 years) of invasive CLBP treatments are important for clinical decision making. Treatment durability, re-intervention rates, and complication rates all inform shared decision making. Results from the treatment arm patients within the Surgical Multi-center Assessment of RF Ablation for the Treatment of Vertebrogenic Back Pain (SMART) RCT demonstrated that improvements in pain and function observed at 3 months were durable up to 2 years [14]. Herein we report the 5-year outcomes for patients treated with BVN ablation for vertebrogenic CLBP in the SMART RCT.

\section{Materials and methods}

\section{Study design}

The SMART trial was a randomized, sham-controlled, double-blind, study (ClinicalTrials.gov-NCT01446419) that was conducted between October 2011 and February 2014. This single-arm, open-label, prospective, follow-up study includes the 5-year outcomes for the US treated patients from the original RCT. The SMART Five Year Follow-up Study is registered on ClinicalTrials.gov as NCT03997825 and was sponsored by Relievant Medsystems, Inc. (Minneapolis, MN). The study was HIPAA compliant and conducted under institutional review board approval and participant informed consent. Enrolled patients maintained their assigned unique participant ID number from the original RCT for comparisons. To reduce potential sources of bias, a central independent research nurse collected all study data. Treatment success was adjudicated by an independent orthopedic surgeon. A third-party statistician (Technomics Research LLC, Minneapolis, MN) conducted the analysis. There were no revisions to the study protocol during the study.

\section{Study participants}

The primary requirements for inclusion in the original RCT were CLBP with a duration greater than 6 months; CLBP nonresponsive to at least 6 months of nonsurgical management; and Modic Type 1 or 2 changes at the vertebral endplates of the levels targeted for treatment. Detailed information about the original study design and randomization process is to be found in the previously published material [13]. An independent panel of three spine surgeons oversaw study enrollment including a review of baseline MRIs for the presence of Modic and evaluation of medical records, clinical assessments, and spine x-rays for exclusion of nonvertebrogenic pain etiologies such as spine instability, stenosis, and nerve impingement. Full inclusion and exclusion criteria confirmed by the panel of independent reviewers are listed in Table 1.

\section{Study sample}

The original SMART RCT study design allowed sham-controlled arm patients the option of crossing to BVN ablation after 1 year of follow-up; $73 \%$ of patients elected to cross to treatment, thus preventing an adequate control sample and a lack of statistical power for future between group comparisons. Due to the high rate of crossover, the RCT converted to a single-arm intrapatient comparison in BVN ablation arm patients after 12 months.

This 5-year follow-up study was conducted in the USA at the 13 study sites that treated patients in the original RCT. Of the 133 US patients treated with BVN ablation, 117 were

Table 1 Inclusion and exclusion criteria

\begin{tabular}{|c|c|}
\hline Inclusion criteria & Exclusion criteria \\
\hline $\begin{array}{l}\text { Skeletally mature patients with chronic ( } \geq 6 \text { months) isolated lumbar } \\
\text { back pain, who had not responded to at least } 6 \text { months of nonoperative } \\
\text { management }\end{array}$ & $\begin{array}{l}\text { Radicular pain (any pain that traveled along a dermatomal distribution } \\
\text { into the lower extremity, causing pain, numbness, and/or weakness/ } \\
\text { heaviness of the affected area) }\end{array}$ \\
\hline Type 1 or Type 2 Modic changes & Previous lumbar spine surgery \\
\hline $\begin{array}{l}\text { Minimum Oswestry disability index (ODI) of } 30 \text { points (100-point } \\
\text { scale) }\end{array}$ & $\begin{array}{l}\text { Symptomatic spinal stenosis (defined as the presence of neurogenic } \\
\text { claudication as confirmed by imaging) }\end{array}$ \\
\hline \multirow[t]{7}{*}{ Minimum Visual Analog Scale (VAS) of 4 cm (10-cm scale) } & Diagnosed osteoporosis $(T<2.5)$ \\
\hline & Disk extrusion or protrusion $>5 \mathrm{~mm}$ \\
\hline & Spondylolisthesis $>2 \mathrm{~mm}$ at any level \\
\hline & 3 or more Waddell's signs of Inorganic Behavior \\
\hline & Beck Depression Inventory (BDI) $>24$ \\
\hline & $\begin{array}{l}\text { Involved in litigation related to back pain or injury or receiving dis- } \\
\text { ability compensation }\end{array}$ \\
\hline & Currently taking extended release narcotics \\
\hline
\end{tabular}


successfully treated and targeted and comprise the per protocol (PP) population for this study. An assessment of potential bias with a USA only study population was conducted. No statistical differences in baseline values or observed clinical outcomes at the 3-month primary endpoint were noted between this US PP study population and the global PP population of the original RCT with a change in ODI of -17.45 in the non-US patients compared to -20.77 in US patients $(p<0.4996)$.

\section{Follow-up study visit}

US treated patients were contacted by study centers to participate in the study. A minimum of two contacts followed by a certified letter was required. The study consisted of a single telephonic study visit between June 2019 and November 2019 (a minimum of 5-year post-BVN ablation). Selfreported patient outcomes were collected via interview using validated questionnaires that were sent in advance of the visit. Data were entered electronically into a secure online clinical database by the independent research nurse.

\section{Study interventions}

The BVN ablation was performed under image guidance in an outpatient setting using the Intracept ${ }^{\circledR}$ System (Relievant Medsystems, Minneapolis, MN, USA). The target zone for BVN ablation is midline in the posterior aspect of the vertebral body, typically between 31 and $50 \%$ from the posterior to anterior of the vertebral body. Mean operative times of 60-90 min were recorded. Detailed information about the surgical technique was previously described [13]. No additional interventions were required in the five plus year follow-up study.

\section{Target success}

MR imaging (T1, T2, and STIR time constants) was performed at 6-week post-RF ablation. Measurements of the degree of overlap between the RF ablation lesion and the terminus of the BVN for each VB were taken by an independent, blinded neuroradiologist reviewer. Targeting success was based on a defined threshold of observed overlap.

\section{Outcome measures}

Functional impact was measured using the Oswestry disability index (ODI) questionnaire [15]. Low back pain was assessed using a Visual Analog Scale (VAS) [16] ranging from 0 (no pain) to 10 (worst pain imaginable). Additional data elements collected were treatments performed postBVN ablation, opioid use in the past 30 days, activity levels, and patient satisfaction. The primary endpoint of this study was a comparison of the minimum of 5-year patientreported ODI compared to baseline. Baseline was defined as the last nonmissing assessment at or before the baseline visit and prior to BVN ablation treatment. Medical records and imaging for surgeries/pain interventions were reviewed by an independent orthopedic surgeon and adjudicated for treatment failure; defined as the same treatment location and etiology as the BVN procedure.

\section{Statistical analysis}

The analysis population was those US treatment arm patients who had successful targeting and provided data at 5 years or more; no participants had imputed data. Assessment for bias in the 5-year study results was conducted. Descriptive statistics of the baseline characteristics of the 5-year study population were means, standard deviations (SDs), number of observations $(N)$, and $95 \%$ confidence intervals (CIs) for continuous variables, and percentages, Ns, and $95 \%$ CIs for categorical variables. Analysis of covariance (ANCOVA) was used for the primary effectiveness endpoint; the change from baseline in ODI score at the last follow-up was analyzed as a function of the baseline ODI score (the covariate). The analyses of secondary endpoints used descriptive statistics as described for the baseline characteristics (above), except for the VAS analysis and the analysis of the regression to the mean. The VAS analysis used an ANCOVA analogous to the primary endpoint. The regression to the mean analysis compared the 12- and 24-month postprocedure results (control and treatment arms) to the 5-year results using $t$ tests of the ODI and VAS scores. An alpha level of 0.05 was used for significance for analyses.

\section{Procedure and targeting success}

Procedure success for all randomized patients was previously described in the RCT [13]. All 133 US treatment arm patients were treated except for one patient with extremely dense bone at S1. In the 132 US treated patients, 117 (88.6\%) were adjudicated as successful for targeting and comprise the US PP study population for this study.

\section{Demographics and baseline characteristics}

Retention rates were high in this study with 100 of the 117 US PP treated patients (85\%) available for review at a mean follow-up of 6.4 years (range 5.4-7.8 years). See Fig. 1 for patient disposition.

Mean age was 47 years, $58 \%$ were male, and $69 \%$ had experienced low back pain for $>5$ years prior to the procedure. In this study population, $80 \%$ of patients had 2 VBs treated and $20 \%$ had three VBs ablated. The most commonly treated VBs were L5 (98\%) and S1 (75\%) followed by L4 
Fig. 1 Consort diagram of patient disposition

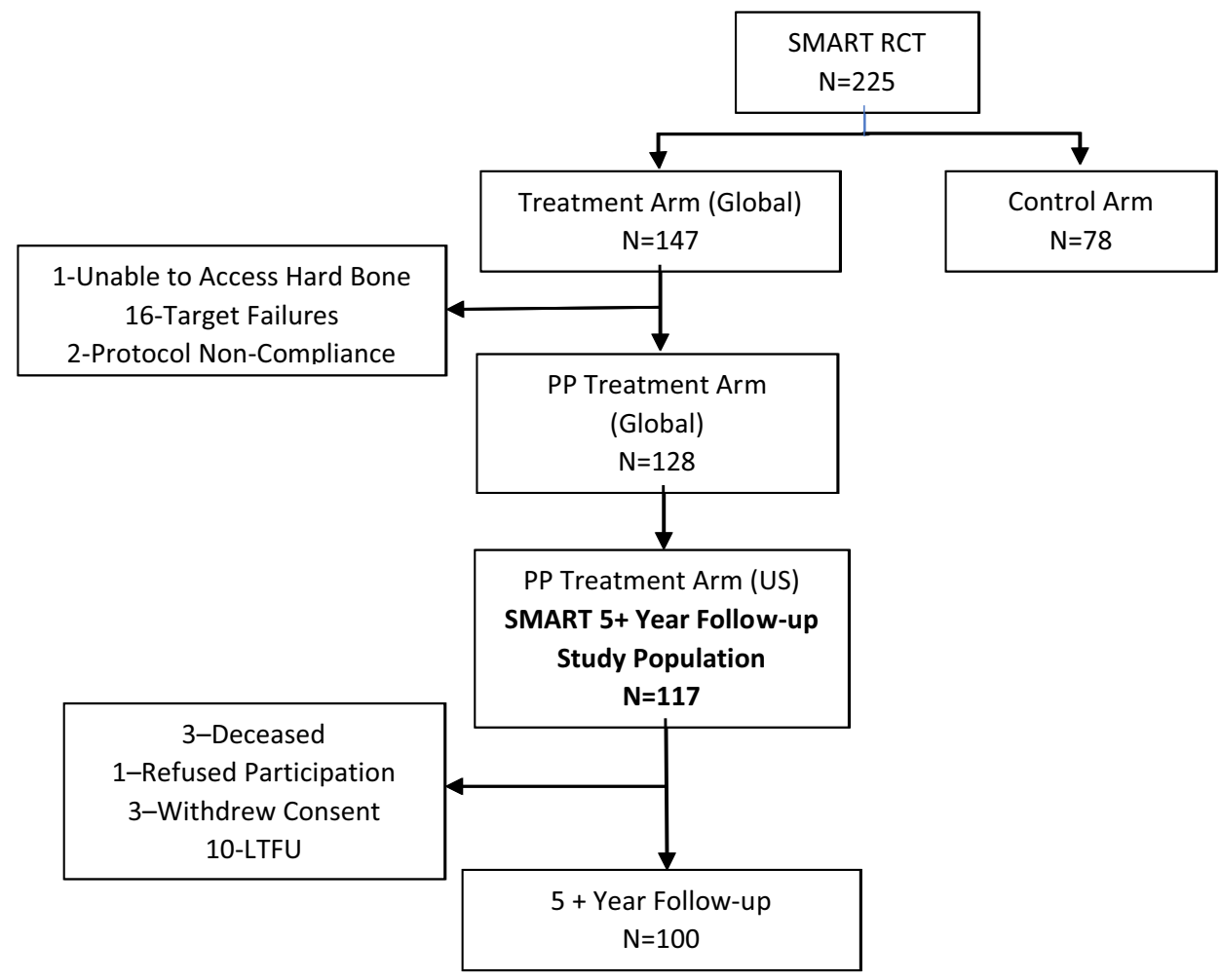

(42\%). A comparison between patients participating in this study $(N=100)$ and the US PP patients that did not participate in the 5-year study visit $(N=17)$ was made. There were no statistically significant differences noted in baseline values or observed clinical outcomes at 3 months between these two groups. See Tables 2 and 3.

\section{Study results}

Long-term results for ODI improvement, VAS improvement, and responder rates were all statistically significant following treatment with BVN ablation.

\section{ODI (primary endpoint)}

At a minimum of 5 years following BVN ablation, patients reported a significant mean reduction in ODI of $25.95 \pm 18.54(60.6 \%)$ compared to a baseline of 42.81 $(p<0.001)$. See Fig. 2 .

\section{VAS pain scores}

Mean reduction in VAS at 5-year post-BVN ablation was significant at $4.38 \pm 2.35$ points on a 10 -point scale from a baseline of $6.74(p<0.001)$. Sixty-six percent $(66 \%)$ of patients reported a $>50 \%$ reduction in VAS, $47 \%$ reported a $>75 \%$ reduction in VAS, and $34 \%$ of patients reported complete pain resolution. See Fig. 3 .

\section{Responder rates}

Using a 15-point improvement in ODI, a commonly accepted minimum clinically important difference (MCID) for functional impact in the treatment of CLBP $[17,18]$, $77 \%(77 / 100)$ of treated patients exhibited a successful response $(p<0.001)$ at 5 years following $\mathrm{BVN}$ ablation. Using a 2-point improvement in VAS, the commonly accepted minimum clinically important difference (MCID) for pain in the treatment of CLBP [19], 88\% (88/100) of treated patients reported a successful response. A combined responder rate of $75 \%$ was demonstrated using thresholds of $\geq 15$-point ODI and $\geq 2$-point VAS improvements for function and pain at 5 years following BVN ablation.

\section{Treatment durability}

Clinically meaningful function and pain levels observed in the treatment arm patients at 1 and 2 years in the original RCT are sustained beyond 5 years of follow-up. See Figs. 4 and 5. Incremental differences between 24-month and 5-year outcomes were statistically significant with a mean incremental reduction of ODI of $3.33(p<0.016)$ and a mean VAS improvement of $0.79(p<0.002)$. 
Table 2 Baseline characteristics

\begin{tabular}{|c|c|c|c|}
\hline Characteristic & $\begin{array}{l}\text { SMART US PP treated subjects in } \\
5+\text { year follow-up } \\
(N=100)\end{array}$ & $\begin{array}{l}\text { SMART US PP treated subjects NOT in } \\
5+\text { year follow-up } \\
(N=17)\end{array}$ & $\begin{array}{l}t \text { test of means or } \\
\text { exact test of propor- } \\
\text { tions }\end{array}$ \\
\hline Age (years) & $47.20+10.91,46,[26,69]$ & $46.06+9.68,48,[27,57]$ & $(p=0.686)$ \\
\hline \multicolumn{4}{|l|}{ Gender } \\
\hline Male & $n=58,58.00 \%$ & $n=13,76.47 \%$ & $(p=0.186)$ \\
\hline Female & $n=42,42.00 \%$ & $n=4,23.53 \%$ & \\
\hline \multicolumn{4}{|c|}{ Duration of LBP symptoms } \\
\hline$<6$ month & $n=0,0.00 \%$ & $n=0,0.00 \%$ & $(p=0.351)$ \\
\hline 6 months to $<1$ year & $n=4,4.00 \%$ & $n=2,11.76 \%$ & \\
\hline 1 year to $<2$ years & $n=11,11.00 \%$ & $n=3,17.65 \%$ & \\
\hline 2 years to $<3$ years & $n=4,4.00 \%$ & $n=1,5.88 \%$ & \\
\hline 3 years to $<5$ years & $n=12,12.00 \%$ & $n=2,11.76 \%$ & \\
\hline$\geq 5$ years & $n=69,69.00 \%$ & $n=9,52.94 \%$ & \\
\hline \multicolumn{4}{|l|}{ Baseline ODI and VAS } \\
\hline Baseline ODI & $42.81+11.57,38,[30,76]$ & $42.12+9.18,40,[30,58]$ & $(p=0.815)$ \\
\hline Baseline VAS & $6.73+1.43,7,[4,10]$ & $6.85+1.21,7,[5,9]$ & $(p=0.761)$ \\
\hline \multicolumn{4}{|l|}{ Vertebral body treated } \\
\hline L3-L4 & $n=2,2.00 \%$ & $n=1,5.88 \%$ & $(p=0.554)$ \\
\hline L4-L5 & $n=20,20.00 \%$ & $n=4,23.53 \%$ & \\
\hline L5-S1 & $n=58,58.00 \%$ & $n=9,52.94 \%$ & \\
\hline L3-L4-L5 & $n=3,3.00 \%$ & $n=1,5.88 \%$ & \\
\hline L4-L5-S1 & $n=17,17.00 \%$ & $n=2,11.76 \%$ & \\
\hline
\end{tabular}

Table 3 Comparison of SMART 3-month primary and secondary endpoint

\begin{tabular}{|c|c|c|c|}
\hline Characteristic & $\begin{array}{l}\text { SMART US PP treated subjects in } 5+ \\
\text { year follow-up } \\
\text { Mean, } N, 95 \% \text { CI } \\
(N=99)^{*}\end{array}$ & $\begin{array}{l}\text { SMART US PP treated subjects NOT in } \\
5+\text { year follow-up } \\
\text { Mean, } N, 95 \% \text { CI } \\
(N=17)\end{array}$ & $\begin{array}{l}t \text { test } p(\text { Ho: } \\
\delta=0) \text { between } \\
\text { groups }\end{array}$ \\
\hline $\begin{array}{l}\text { Change in ODI } \\
\text { (Baseline to } 3 \text { months) }\end{array}$ & $-20.83,99.00,[-23.78,-17.87]$ & $-20.47,17.00,[-28.48,-12.46]$ & $(p=0.927)$ \\
\hline $\begin{array}{l}\text { Change in VAS } \\
\text { (Baseline to } 3 \text { months) }\end{array}$ & $-3.03,99.00,[-3.55,-2.52]$ & $-2.18,17.00,[-3.31,-1.05]$ & $(p=0.203)$ \\
\hline $\begin{array}{l}\text { ODI responders } \\
\text { ( } \geq 10 \text {-point ODI reduction) }\end{array}$ & $n=75,75.76 \%$ & $n=13,76.47 \%$ & $(p=1.000)$ \\
\hline
\end{tabular}

*Observed data, no imputation for missing visit

\section{Post-BVN ablation healthcare utilization}

At baseline 30/100 patients (30\%) were actively taking opioids at least once a week. At 5 years, only 8/100 patients (8\%) were actively taking opioids, a reduction of $73 \%$. An additional $4 / 100$ patients (4\%) were taking opioids less than 1 time per week.

Injections were also significantly reduced in this group of patients at 5 years compared to baseline. At baseline, $59 / 100$ patients $(59 \%)$ had received an injection in the prior 12 months. At 5 years, only 4/100 patients (4\%) had received injections in the prior 12 months. Only one of these (1\%) was for the same treatment location and etiology for which BVN ablation was undertaken.

Twenty-one patients had surgery, or an interventional pain procedure performed in the mean of 6.4-year postBVN ablation. Ten of these were adjudicated by the independent reviewer as not related to the original CLBP for which the patient underwent the BVN procedure and included L2 burst fracture (1), spinal stenosis (1), spondylolysis at different level (1), disk herniation at a different level (4), and spondylosis at a different level (3). Eleven (11\%) were adjudicated as related to the original location and etiology of axial back pain and included fusion (8) 


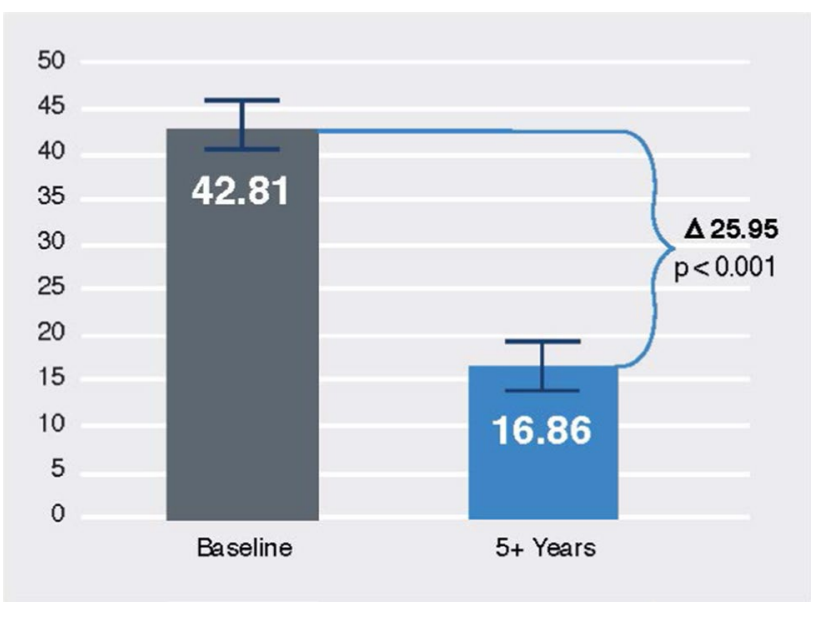

Fig. 2 Bar graph with confidence intervals for the primary endpoint, mean ODI at baseline, and a minimum of 5 years in BVN-treated US PP patients. The mean reduction in ODI of 25.95 points was statistically significant $(p<0.001)$

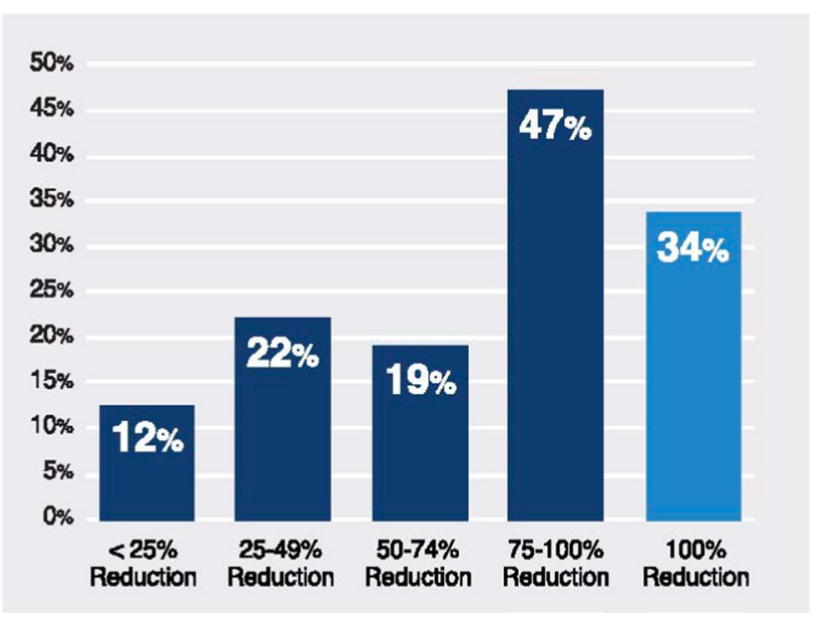

Fig. 3 Proportion of patients by percent mean improvement in VAS from baseline to a minimum of 5 years of follow-up. Sixty-six percent $(66 \%)$ of patients reported a $>50 \%$ reduction in VAS $(p<0.04)$, $47 \%$ reported a $>75 \%$ reduction in VAS, and $34 \%$ of patients reported complete pain resolution

and facet RF ablation (3). There were no patient-reported complications at the 5-year follow-up.

To understand any potential impact of additional treatments on clinical outcomes, an analysis was performed between the "as-treated" and the "BVN ablation only" populations in this study. There were no significant differences in 5-year outcomes noted with ODI reductions or pain scores between these two groups. See Table 4.

\section{Patient satisfaction}

Patients reported a high degree of patient satisfaction: $70 \%$ (70/100) rated their condition as improved; $27 \%$ reported no change; and $3 \%$ indicated their condition had worsened. Seventy-nine percent (79\%) of patients indicated they would have the BVN ablation again for the same condition, and $65 \%$ reported that they had resumed their level of activity that they had enjoyed prior to low back pain.

\section{Discussion}

This report details the outcomes at the minimum 5-year endpoint of the US patients with CLBP and Modic Type 1 or 2 changes from L3-S1 who underwent BVN ablation as a part of the SMART trial, a level I, sham-controlled RCT. The primary outcome of mean change in patient-reported function on the ODI was highly statistically significant with BVN ablation treated patients reporting a mean reduction in ODI of 25.95 compared to a baseline of $42.81(p<0.001)$. These differences were well above established thresholds for clinical significance. The study's secondary outcomes, including pain score and responder rates, also demonstrated statistically significant improvements from baseline. Nearly half of the patients reported a $75 \%$ or greater reduction in pain, and more than one-third reported complete pain resolution at a mean follow-up of 6.4-year post-BVN ablation treatment.

Very few high-level studies have published results beyond 2 years for the treatment of CLBP. At a mean of 12.8 years, Hedlund et al. [20] reported an ODI reduction of 10.5 points for the fusion arm of the Swedish lumbar spine study. Brox et al. reported 4-year follow-up of surgical versus cognitive behavioral therapy (CBT) and exercise. At 4 years ODI decreased 14.4 points (from 44.1 to 29.7) in the fusion arm and 16.4 points (from 43.4 to 27.0) in the CBT/exercise arm. In the current study, post-BVN ablation improvements in ODI at 5 years were 25.95 points, a difference of greater than 9.5 points over CBT and exercise [21].

These long-term results demonstrating durability of outcomes post-BVN ablation are remarkable given that progressive degenerative changes are known to occur in the spine over time. Despite this, we did not observe deterioration in clinical outcomes over time. Neither was there evidence of regression toward baseline. On the contrary, these data showed maintenance of short and intermediate outcomes through a mean of 6.4-year post-BVN ablation. The longevity of improvements in pain and function observed from baseline to 1,2 , and 5 years is supported by large animal studies that demonstrate a lack of organized nerve regrowth at 1-year post-BVN ablation. This lack of regrowth can be attributed to the inability of the nerve sprouts to span the 


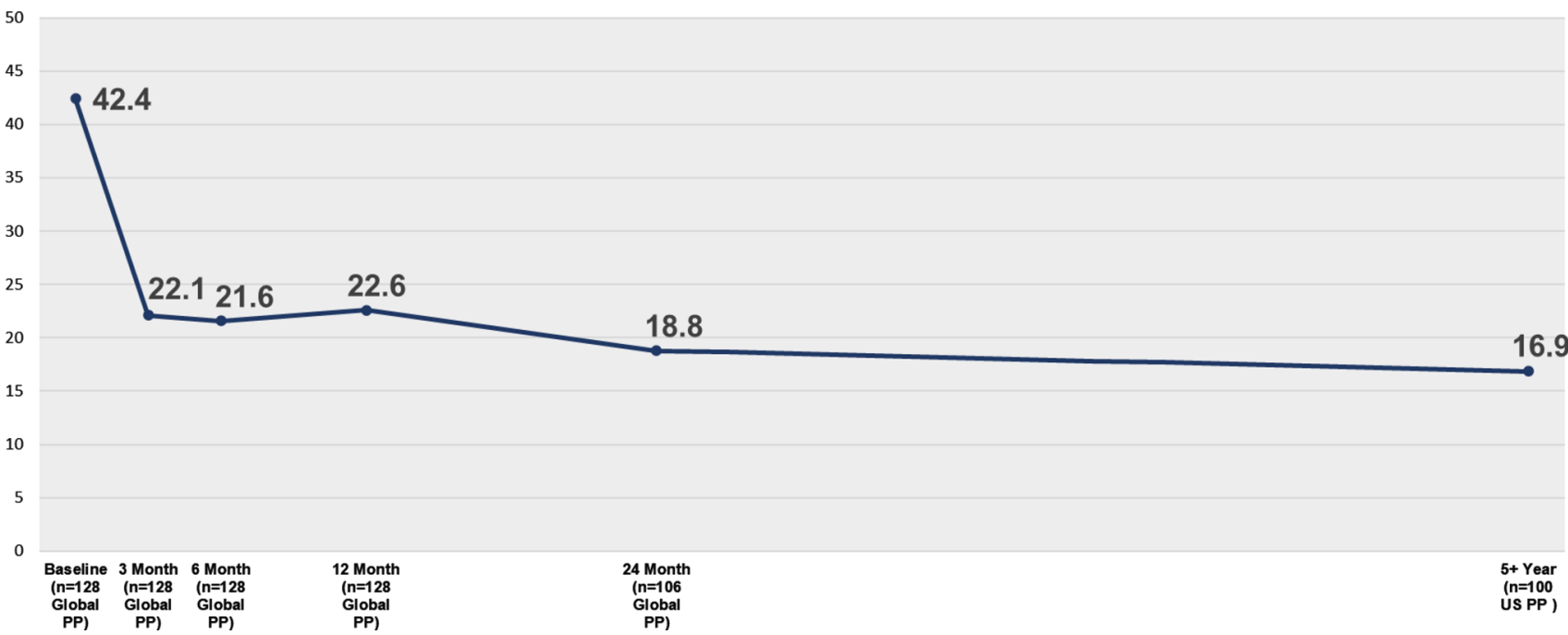

Fig. 4 Mean ODI over time. Differences in ODI from baseline are statistically significant in US PP patients treated with BVN ablation at a minimum follow-up of 5 years $(p<0.001)$

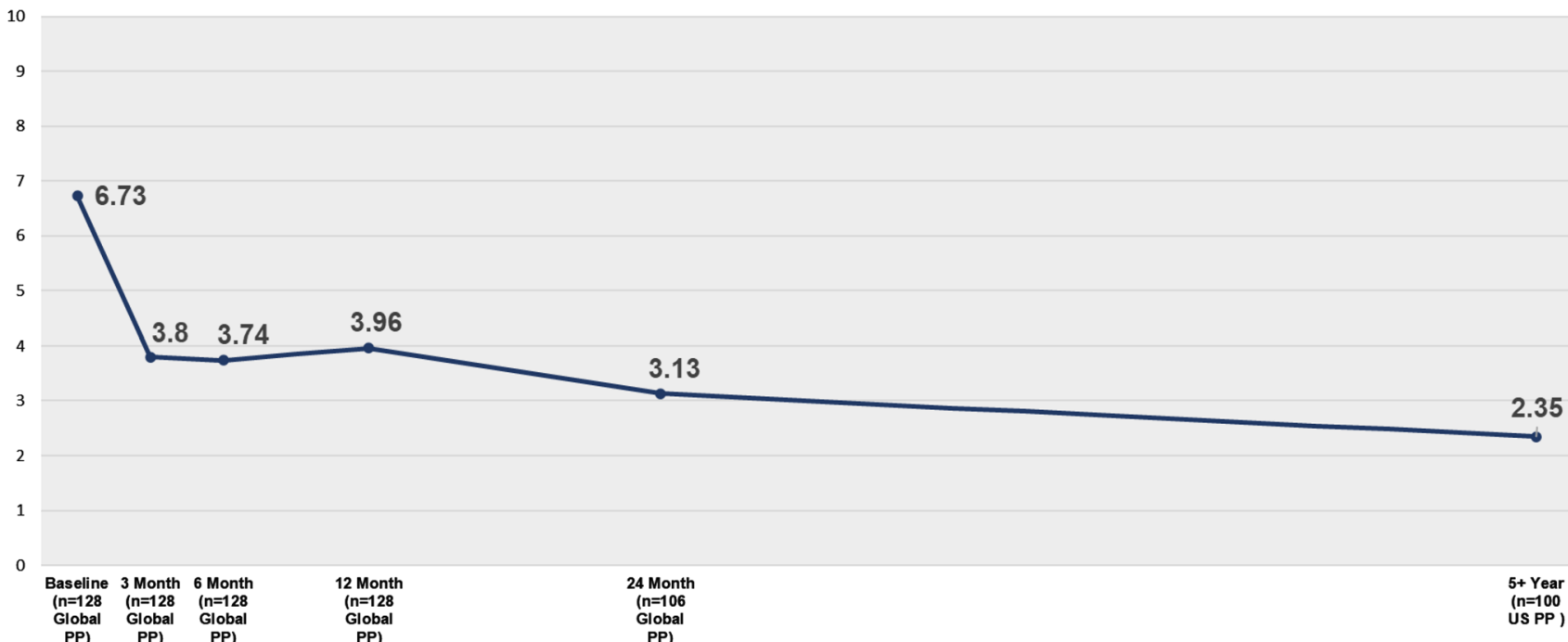

Fig. 5 Mean VAS over time. Differences in VAS from baseline are statistically significant in US PP patients treated with BVN ablation at a minimum follow-up of 5 years $(p<0.001)$

Table 4 Comparison of SMART $5+$ years endpoints

\begin{tabular}{llll}
\hline Characteristic & $\begin{array}{l}\text { SMART US PP treated subjects in } \\
\text { 5+ year follow-up BVN ablation only } \\
\text { Mean, } N, 95 \% \text { CI } \\
(N=79)\end{array}$ & $\begin{array}{l}\text { SMART US PP treated subjects in 5+ year } \\
\text { follow-up BVN ablation + procedure/intervention } \\
\text { Mean, N, 95\% CI } \\
(N=21)\end{array}$ & $\begin{array}{l}t \text { test } p(\text { Ho: } \delta=0) \text { or } \\
\text { exact test between } \\
\text { groups }\end{array}$ \\
\hline $\begin{array}{l}\text { Change in ODI } \\
\text { (Baseline to 5 years })\end{array}$ & $-25.76,79.00,[-30.10,-21.42]$ & $-26.67,21.00,[-33.64,-19.70]$ & $(p=0.843)$ \\
$\begin{array}{l}\text { Change in VAS } \\
\text { Baseline to 5 years })\end{array}$ & $-4.25,79.00,[-4.78,0.00]$ & $-4.90,21.00,[-5.90,-3.89]$ & $(p=0.266)$
\end{tabular}


1-cm ablation zone, as well as the fact that the intraosseous portion of the BVN is non- or thinly myelinated [22].

Preclinical studies showed no evidence of negative effect on tissues outside the ablation zone [22]. Histologic data demonstrated that existing boney trabecular structure is not damaged with the procedure and that at 3 months new bone formation and thickening trabeculae are widespread. Over the long term (6 months and 1 year), there are a fatty replacement of bone marrow, a thickening of remaining trabecular bone elements, and concurrent regeneration of blood vascular network [22]. There have been 378 human clinical trial participants treated with BVN ablation to date with controlled collection of adverse events. Only one compression fracture has been reported in a sham-controlled crossover participant with a diagnosis of osteopenia that was taking high doses of estrogen therapy. The fracture healed spontaneously by 8 weeks without sequalae.

It is notable that incremental improvements in ODI and VAS were statistically significant between 24 months and 5 years. Patients with CLBP are known to engage in a downward spiral of pain, deactivation, and disability. We theorize that at least a portion of the progressive improvements noted over time are the result of reversing that spiral as patients increase their activity level with less pain. It is also possible that patients who were happier with their outcomes were more likely to respond, thus biasing the results. However, the high response rate (85\%) and the lack of statistical differences between the study population and lostto-follow-up population suggest that this was not the case. Likewise, the very low rates of injections and opioids use would argue against these co-interventions impacting the 5 -year outcomes.

In this study, $8 \%$ of patients progressed to a fusion and $3 \%$ had a facet RF ablation performed at the BVN treatment location. Interestingly, the additional procedures did not appear to significantly impact ODI and VAS outcomes in this group of patients when compared to outcomes in BVN ablation only treated patients. Noteworthy is that five of the eight patients that progressed to fusion were at a single study site. Thus, the incidence of lumbar fusion post-BVN ablation may be over-stated in this trial's results and not reflective of future outcomes in most clinical practices.

While these long-term results provide perspective on the durability of BVN ablation beyond 5 years, they do not suggest that BVN ablation is a better treatment for all people with CLBP. Rather, this study adds to the evidence that BVN ablation is a highly effective and durable treatment for a specific subgroup of patients with CLBP characterized by the clinical and radiographic criteria outlined in this study's methods.

\section{Strengths and limitations}

Strengths of the study include the high retention rate of $85 \%$ through a mean follow-up of 6.4 years as well bias reduction through the collection of data by an independent research nurse, independent adjudication of treatment success, and analysis of results by a third-party statistician. Potential criticisms include the conduct of the study in the USA only (though analyses suggest this did not bias the results), the lack of a control group (inadequate control sample due to a $73 \%$ crossover rate of the sham-treated group in the original trial), and industry funding of the study.

\section{Conclusion}

BVN ablation is a safe and effective minimally invasive treatment for the relief of chronic low back pain in patients with Type 1 and/or 2 Modic changes. Patients treated for axial CLBP with BVN ablation exhibited sustained and significant clinical benefits in ODI and VAS and maintained high responder rates at a mean of 6.4 years following treatment. BVN ablation demonstrates durable relief of CLBP and less injection and opioid utilization in a patient population that typically has few effective treatment options.

\section{Compliance with ethical standards}

Conflict of interest Nothing to disclose: The following authors have nothing to disclose: Kamrava, Yeung, Truumees, Yuan, DePalma, Anderson, Buxton, Reynolds, and Sikorsky. Consultancy for relievant: The following authors report consultancy for physician training and advisory roles within relievant: Fischgrund, Rhyne, Macadaeg, Schaufele, and Moore.

Research oversight and ethics This research was conducted under the oversight of the Western Institutional Review Board and the investigational site's local IRB. This research was conducted in accordance with the Helsinki Declaration.

Informed consent Informed consent was obtained for participants in this study.

Open Access This article is licensed under a Creative Commons Attribution 4.0 International License, which permits use, sharing, adaptation, distribution and reproduction in any medium or format, as long as you give appropriate credit to the original author(s) and the source, provide a link to the Creative Commons licence, and indicate if changes were made. The images or other third party material in this article are included in the article's Creative Commons licence, unless indicated otherwise in a credit line to the material. If material is not included in the article's Creative Commons licence and your intended use is not permitted by statutory regulation or exceeds the permitted use, you will need to obtain permission directly from the copyright holder. To view a copy of this licence, visit http://creativecommons.org/licenses/by/4.0/. 


\section{References}

1. Lotz JC, Fields AJ, Liebenberg EC (2013) The role of the vertebral end plate in low back pain. Global Spine J 3(3):153-164. https://doi.org/10.1055/s-0033-1347298

2. Dudli S, Fields AJ, Samartzis D, Karppinin J, Lotz JC (2016) Pathobiology of modic changes. Eur Spine J 25(11):3723-3734. https://doi.org/10.1007/s00586-016-4459-7

3. Munir S, Freidin MB, Rade M, Määttä J, Livshits G, Williams FMK (2018) Endplate defect is heritable, associated with low back pain and triggers intervertebral disc degeneration: a longitudinal study from twinsUK. Spine 43(21):1496-1501. https://doi. org/10.1097/BRS.0000000000002721

4. Dudli S, Sing DC, Hu SS, Berven SH, Burch S, Deviren V et al (2017) ISSLS PRIZE IN BASIC SCIENCE 2017: intervertebral disc/bone marrow cross-talk with Modic changes. Eur Spine J 26(5):1362-1373. https://doi.org/10.1007/s00586-017-4955-4

5. Fras C, Kravetz P, Mody DR, Heggeness MH (2003) Substance P-containing nerves within the human vertebral body. An immunohistochemical study of the basivertebral nerve. Spine J. 3(1):63-67

6. Bailey JF, Liebenberg E, Degmetich S, Lotz JC (2011) Innervation patterns of PGP 9.5-positive nerve fibers within the human lumbar vertebra. J Anat 218(3):263-270. https://doi.org/10.111 1/j.1469-7580.2010.01332.x

7. Modic MT, Steinberg PM, Ross JS, Masaryk T, Carter J (1988) Degenerative disk disease: assessment of changes in vertebral body marrow with MR imaging. Radiology 166(1 Pt 1):193-199. https://doi.org/10.1148/radiology.166.1.3336678

8. Ulrich JA, Ellen BS, Liebenberg EC, Thuillier DU, Lotz J (2007) ISSLS prize winner: repeated disc injury causes persistent inflammation. Spine (Phila Pa 1976) 32(25):2812-2819. https://doi. org/10.1097/brs.0b013e31815b9850

9. Antonacci MD, Mody DR (1998) Heggeness MH (1998) Innervation of the human vertebral body: a histologic study. J Spinal Disord 11(6):526-531

10. Becker S, Hadjipavlou A, Heggeness MH (2017) Ablation of the basivertebral nerve for treatment of back pain: a clinical study. Spine J 17(2):218-223

11. Truumees E, Macadaeg K, Pena E, Arbuckle J, Gentile J, Funk R et al (2019) A prospective, open-label, single-arm, multi-center study of intraosseous basivertebral nerve ablation for the treatment of chronic low back pain. Eur Spine J 28(7):1594-1602

12. Khalil J, Smuck M, Koreckij T, Keel J, Beall D, Goodman B et al (2019) A prospective, randomized, multi-center study of intraosseous basivertebral nerve ablation for the treatment of chronic low back pain. Spine J 19:1620-1632

13. Fischgrund JS, Rhyne A, Franke J, Sasso R, Kitchel S, Bae H et al (2018) Intraosseous basivertebral nerve ablation for the treatment of chronic low back pain: a prospective randomized double-blind sham-controlled multi-center study. Eur Spine J 27(5):1146-1156

14. Fischgrund JS, Rhyne A, Franke J, Sasso R, Kitchel S, Bae H et al (2019) Intraosseous basivertebral nerve ablation for the treatment of chronic low back pain: two-year results from a prospective randomized double-blind sham-controlled multi-center study. Int J Spine Surg 13(2):1-10

15. Roland M, Fairbank J (2000) The Roland Morris disability questionnaire and the Oswestry disability questionnaire. Spine 25(24):3115-3124

16. Price DD, McGrath PA, Rafii A, Buckingham B (1983) The validation of visual analogue scales as ratio scale measures for chronic and experimental pain. Pain 17(1):45-56

17. Ostelo RW, de Vet HC (2005) Clinically important outcomes in low back pain. Best Pract Res Clin Rheumatol 9(4):593-607. https ://doi.org/10.1016/j.berh.2005.03.003

18. Hagg O, Fritzell P, Nordwall A (2003) The clinical importance of changes in outcome scores after treatment for chronic low back pain. Eur Spine J 12(1):12-20. https://doi.org/10.1007/s0058 6-002-0464-0

19. Copay AG, Glassman SD, Subach BR, Berven S, Schuler TC, Carreon LY (2007) Minimum clinically important difference in lumbar spine surgery patients: a choice of methods using the Oswestry Disability Index, Medical Outcomes Study Questionnaire Short Form 36, and pain scales. Spine J 8(6):968-974. https ://doi.org/10.1016/j.spinee.2007.11.006

20. Hedlund R, Johansson C, Hägg O, Fritzell P, Tullberg T (2016) The long-term outcome of lumbar fusion in the Swedish lumbar spine study. Spine J 16:579-587

21. Brox JI, Nygaard OP, Holm I, Keller A, Ingebrigtsen T, Reikeras O (2010) Four-year follow-up of surgical versus non-surgical therapy for chronic low back pain. Ann Rheum Dis 69:1643-1648. https://doi.org/10.1136/ard.2009.108902

22. Lotz JC. Basivertebral nerve ablation chronic results pre-clinical study for University of California San Francisco. Unpublished

Publisher's Note Springer Nature remains neutral with regard to jurisdictional claims in published maps and institutional affiliations.

\section{Affiliations}

\section{Jeffrey S. Fischgrund ${ }^{1}\left(\mathbb{D} \cdot\right.$ Alfred Rhyne $^{2} \cdot$ Kevin Macadaeg $^{3} \cdot$ Gregory Moore $^{4} \cdot$ Evish Kamrava $^{5} \cdot$ Christopher Yeung $^{6}$. Eeric Truumees ${ }^{7} \cdot$ Michael Schaufele $^{8} \cdot$ Philip Yuan $^{9} \cdot$ Michael DePalma $^{10} \cdot$ David Greg Anderson ${ }^{11}$. Douglas Buxton ${ }^{12} \cdot$ James Reynolds $^{13} \cdot$ Michael Sikorsky $^{14}$}

1 William Beaumont Hospital, Oakland University School of Medicine, 3601 W 13 Mile Road, Royal Oak, MI 48073, USA

2 OrthoCarolina Spine Center, 2001 Randolph Road, Charlotte, NC 28207, USA

3 Indiana Spine Group, 13225 North Meridian Street, Carmel, IN 46032, USA

4 Pacific Sports and Spine, 74B Centennial Loop, Suite 300, Eugene, OR 97401, USA
5 The Spine Institute, 2811 Wilshire Boulevard, Suite 850, Santa Monica, CA 90403, USA

6 Desert Institute for Spine Care, 1635 E Myrtle Avenue, Suite 400, Phoenix, AZ 85020, USA

7 Seton Spine \& Scoliosis Center, 1600 West 38th Street, Suite 200, Austin, TX 78731, USA

8 Drug Studies America, 400 Tower Road NE, Suite 150, Marietta, GA 30060, USA 
9 Memorial Orthopedic Surgical Group, Department of Surgery, Long Beach Memorial Medical Center, 2760 Atlantic Avenue, Long Beach, CA 90806, USA

10 Virginia iSpine Physicians, 9020 Stony Point Parkway, S-140, Richmond, VA 23235, USA

11 Rothman Orthopedic Institute, 3300 Tillman Drive, 2nd Floor, Glenview Corporate Center, Bensalem, PA 19020, USA
12 Maine Medical Partners Neurosurgery and Spine, 195 Fore River Parkway, Suite 490, Portland, ME 04102, USA

13 Spine Care Medical Group, 455 Hickey Boulevard, Suite 310, Daly City, CA 94015, USA

14 Michigan Orthopedic Institute, 26025 Lahser Road, Suite 200B, Southfield, MI 48033, USA 